\title{
A Floating Drag-Plate Lysimeter for Atmospheric Boundary Layer Research
}

\author{
WILSON B. GODDARD \\ Dept. of Agricultural Engineering, University of California, Davis \\ (Manuscript received 9 September 1969, in revised form 20 February 1970)
}

\begin{abstract}
The description is presented of the design, calibration and operation of a 100-ton, floating, drag-plate lysimeter used both for measurement of atmospheric shear stress and evapotranspiration from a growing grass turf. Calibration and operational procedures are outlined with estimates of static and measurements of dynamic errors along with typical drag-force records.

Unique fea tures of the $6 \mathrm{~m}$ diameter drag plate include a growing grass turf comparable to the surrounding 5-hectare field site, vectorial recording of the surface shear stress each $24 \mathrm{sec}$ by means of a modern data acquisition system, and evapotranspiration measurement of the contained grass turf each 2 min on the data logging system.

The drag plate has been an integral part of the atmospheric boundary layer research at Davis where flux-gradient and energy balance relationships have been studied. Preliminary findings of the momentum transfer analysis are given and previously reported results are referenced.
\end{abstract}

\section{Introduction}

Atmospheric shear stress, usually expressed in terms of the friction velocity, $U_{*}=\sqrt{\tau / \rho}$, where $\tau$ is the shear stress and $\rho$ the air density, has been shown to be an important, fundamental parameter in boundary layer transfer processes of heat, mass and momentum (Schlichting, 1960; Hinze, 1959; Priestley, 1959; Monin and Obukhov, 1954). The difficulties involved in measuring this important parameter have been a limiting factor in boundary layer research. Methods developed to estimate $\tau$ from wind velocity profile measurements are indirect and rely on some measurement of atmospheric stability. Direct measurement of the average product of the horizontal and vertical wind velocity fluctuations, $\overline{u^{\prime} w^{\prime}}$, requires instrumentation with very fast time constants of the order of 0.01 sec, directional stability to accurately determine the mean horizontal wind direction, and high-speed data logging or precision analog computation and integration. For these reasons, computation of atmospheric shear stress, through the Reynolds' technique is a very difficult instrumentation problem. Measurement of surface drag force under the condition of no horizontal pressure gradients is considered by most atmospheric research groups as being a direct technique. It was for these reasons that the drag-plate approach was adopted in the atmospheric boundary layer research conducted at the University of California, Davis.

\section{Review of atmospheric drag-force measurements}

A number of atmospheric boundary layer research groups have previously used drag plates to determine shear stress, although most investigations lacked supporting measurements of concurrent flux-gradient relationships of heat, mass and momentum. Sheppard (1947) investigated the shear stress across a $160 \mathrm{~m}$ diameter concrete apron with a $22.5-\mathrm{cm}$ diameter oil floating aluminum drag plate. The system was oriented into the prevailing wind with the position of a torsion restraining member visually recorded each 6 sec during each 10-min run. Pasquill (1950) improved on the Sheppard design by including a drum recording system, increasing the diameter of the drag plate to $45.7 \mathrm{~cm}$ and by installing a soil sod holder for grass turf. Rider (1954) extended this same work by arranging an array of six Pasquill drag plates, in $40^{\circ}$ increments tangential to an $8 \mathrm{~m}$ radius circle. The resulting array allowed variations of $200^{\circ}$ in wind direction by reference to the plate most nearly in line with the wind direction. Poppendiek and Vehrencamp (1950) conducted investigations under desert conditions using a $91.5-\mathrm{cm}$ diameter drag plate similar to the Sheppard design. The water floating drag plate's position was visually observed and manually recorded. Vehrencamp (1952) added an electromechanical servo-system which virtually eliminated the drag-plate movement and provided rectangular component measurement of drag force which allowed the system to operate independent of wind direction. A comparison of the Vehrencamp and Sheppard design was reported by Lettau and Davidson (1957). Sterns (1962), at frozen Lake Mendota, operated an ice-block drag plate during studies conducted by the University of Wisconsin. Bradley (1968a) designed a portable strain gage drag plate with vectorial recording and integration. A mechanized calibration system greatly simplified field calibration and flotation was eliminated 


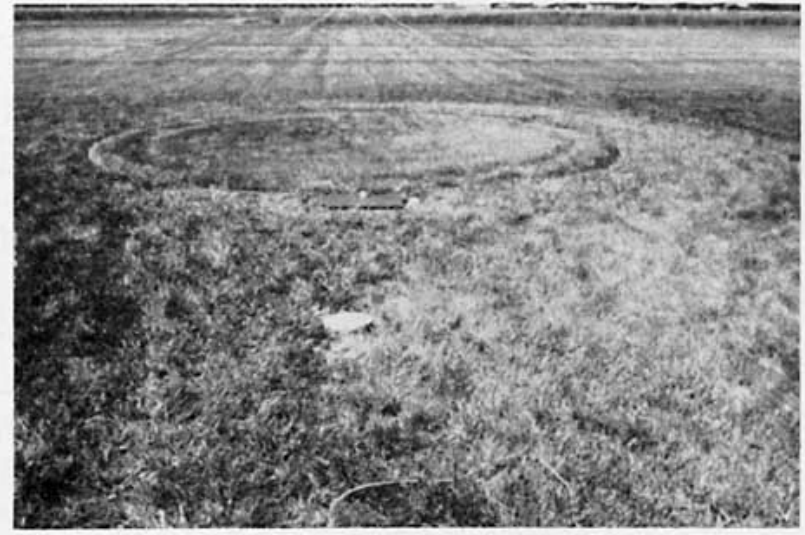

FIG. 1. Field site of the floating drag-plate lysimeter, University of California, Davis.

by a wire suspension system. Bradley had two designs, one a portable $45-\mathrm{cm}$ diameter plate and the other a 91-cm diameter heavy duty system suitable for grass sod turf samples. Bradley's (1968b) study of velocity profile-shear stress relationships over changes of surface roughness illustrates how even across complex transitional zones, measured shear stress enables description of the momentum transfer.

\section{U. C. floating drag-plate lysimeter}

The U. C. drag-plate field installation is shown in Fig. 1 with a cross-sectional drawing of the system in Fig. 2. The drag plate floats in water narrowly confined between an outer wall and the floating inner soil tank. The grass turf soil container is $6 \mathrm{~m}$ in diameter by $1 \mathrm{~m}$ deep and is very similar to that described by Pruitt and Angus (1960). The soil tank and upper outer retaining wall are of $6.3-\mathrm{mm}$ fiberglass which is both watertight and resistant to corrosion. The drag plate's flotation unit extends $1.16 \mathrm{~m}$ below the soil tank and is made of styrofoam logs encapsulated in polyurethane foam with a fiberglass exterior. Within the flotation unit there are 60 drainage and ballast tanks, $30 \mathrm{~cm}$ in diameter by 90 $\mathrm{cm}$ deep, which are used for soil moisture control and

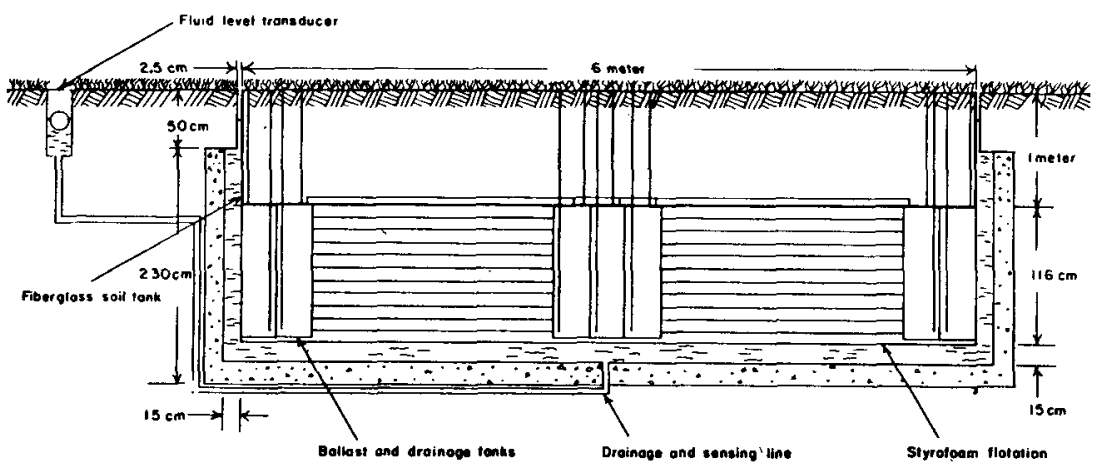

FIG. 2. Cross section of the floating drag-plate lysimeter.

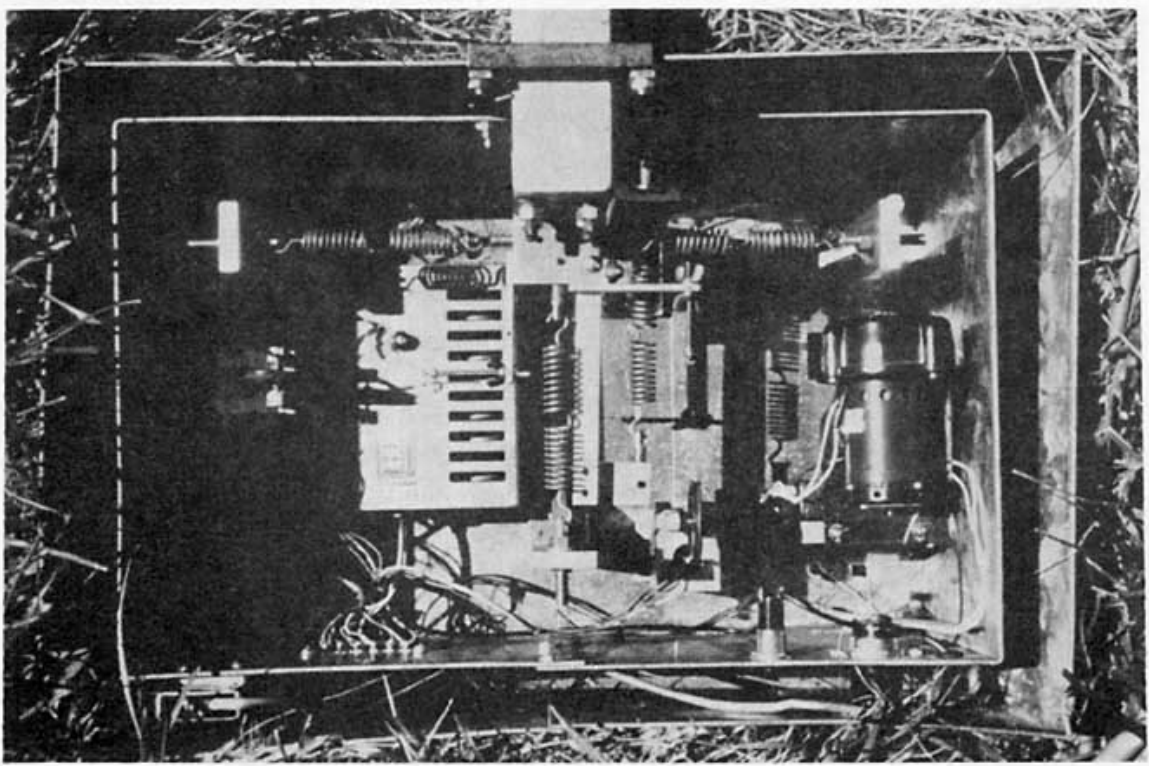

FIG. 3: Drag-force transducer system, east side: 


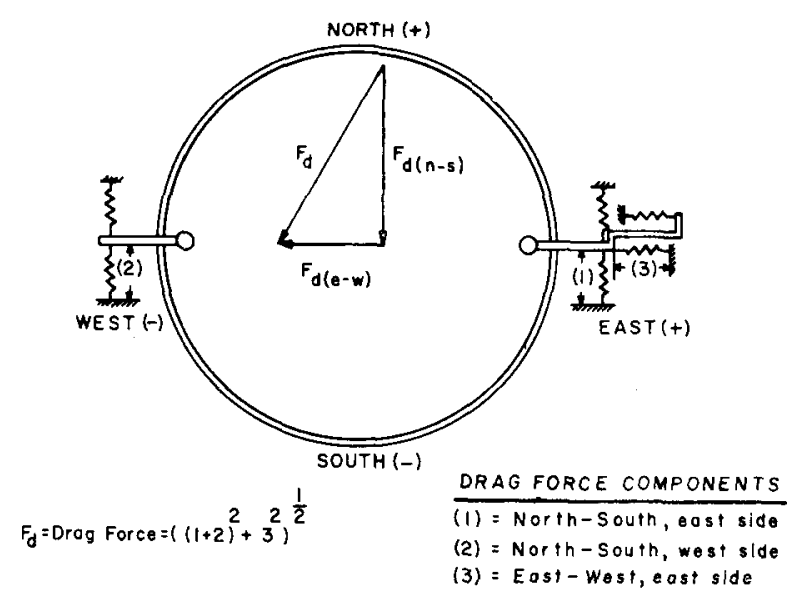

Fig. 4. Schematic of drag-force transducer system.

floating height and attitude adjustment. The total floating weight of the drag plate is 52 metric tons and is sensitive to horizontal forces $<20 \mathrm{gm}$.

'The drag force transducers shown in Fig. 3 are located in surface-level temperature controlled $(50 \pm 0.5 \mathrm{C})$ boxes, one on each side on a east-west line bisecting the drag plate. The drag-force measurement is made by linear differential transformers following the displacement of linear counter-wound pre-loaded restraining springs. The linear differential transformers yield dc outputs proportional to the vectorial drag-force components. Movement of the soil tank is transferred to the drag-force transducers by two aluminum arms which are bolted to a steel member which bisects the soil tank in the east-west direction. A schematic of the vectorial drag force transducer system is shown in Fig. 4. Evapotranspiration from the growing grass turf is measured as a function of water height in an adjacent stilling well by use of a float-actuated submerged, linear differential transformer (Lourence and Goddard 1967).

\section{Calibration, operation and data reduction}

Each field investigation with the drag plate requires a calibration through application of known horizontal forces in each of the cardinal directions. The range of forces applied covers all usual boundary layer shearstress conditions up to $3.4 \mathrm{dyn} \mathrm{cm}^{-2}$. A $7 \mathrm{~m}$ plastic canopy shown in Fig. 5 is placed over the drag plate to exclude wind effects, after which a set of weights are applied as shown in Fig. 6 . The steady-state dc voltages are then recorded and a best fit line applied to the calibration data for use in data reduction.

During a field investigation, the three drag-force components are recorded every $24 \mathrm{sec}$ on a digital data acquisition system and each $5 \mathrm{sec}$ on a strip chart point recorder. Fig. 7 is a typical point record with the top two traces are the north-south drag components, the third the east-west drag component, and the bottom the

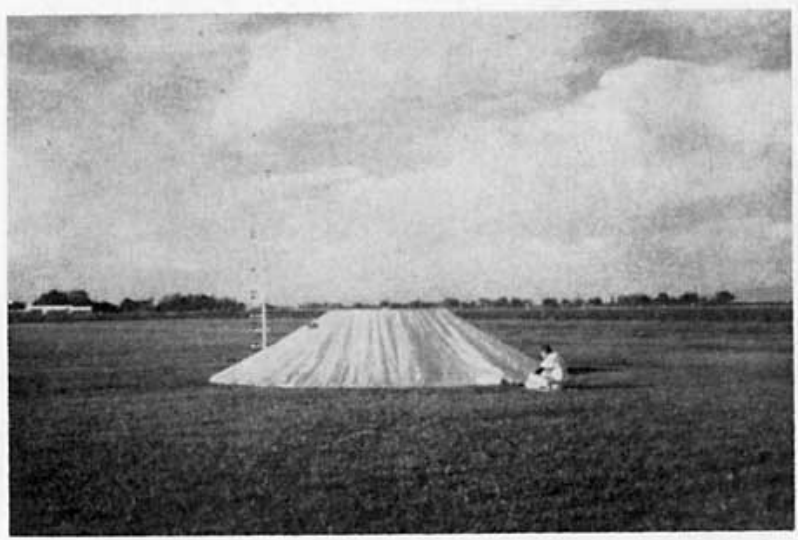

ifIs. 5. Drag-plate calibration cover.

wind speed at $2 \mathrm{~m}$. The natural periodicity of the system is shown by the strong oscillations in the record.

A point-by-point data reduction is carried out on the 7044 IBM computer using individual calibrations (dyn $\mathrm{cm}^{-2} \mu \mathrm{V}^{-1}$ ) for each transducer. The absolute values of the drag force vectors are then averaged over $\frac{1}{2} \mathrm{hr}$ periods and used to compute the average drag force $\tilde{\tau}$

$$
\bar{\tau}=\left[\left(\frac{\mathrm{NSE}+\mathrm{NSW}}{2}\right)^{2}+(\mathrm{EWE})^{2}\right]^{\frac{1}{2}}
$$

where NSE is the north-south drag transducer on the east side, NSW the north-south drag transducer on the west side, and EWE the east-west drag transducer on the east side. The absolute magnitude is used since we are interested in the average horizontal shear stress.

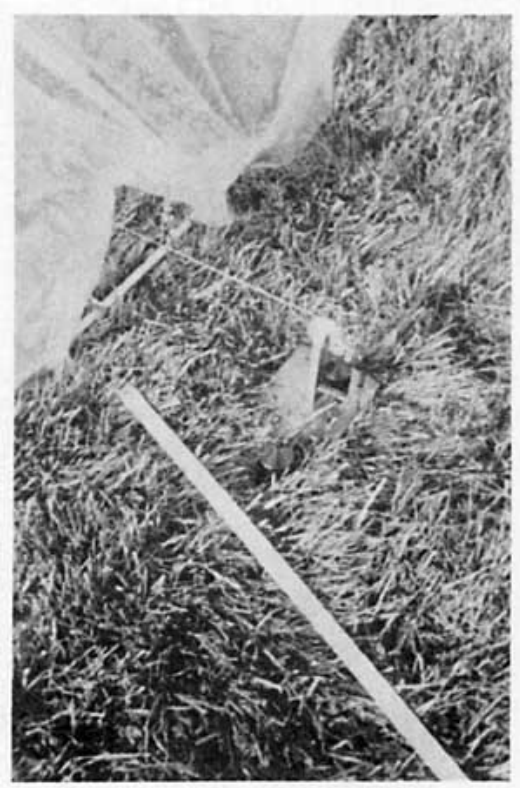

FIG. 6. Drag-plate calibration procedure. 


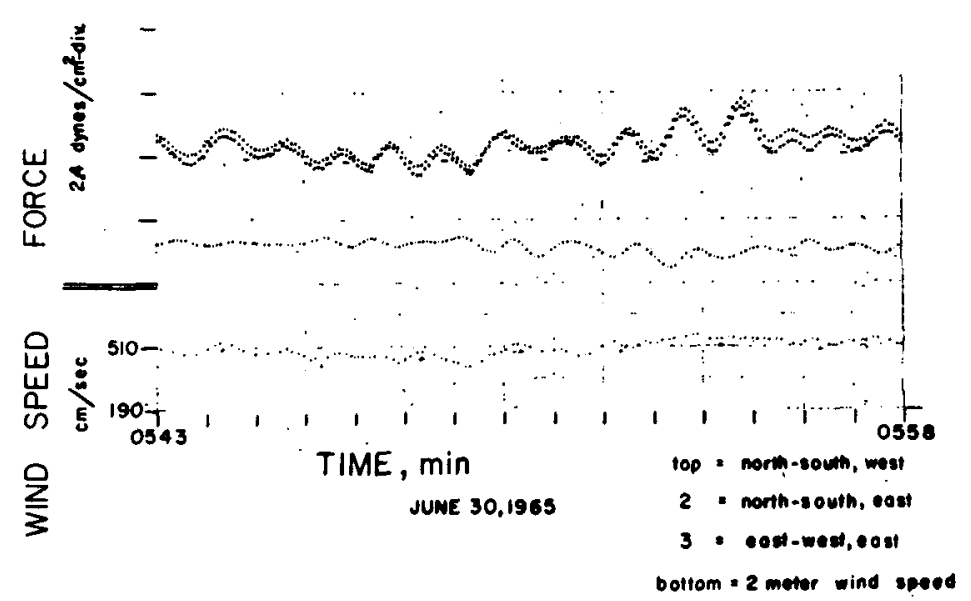

FIG. 7. Typical drag-force vectorial component record.

\section{Error analysis and preliminary findings}

The sensitivity of the drag plate system is $2 \times 10^{-3} \mathrm{dyn}$ $\mathrm{cm}^{-2}$, although the absolute uncertainty is about $\pm 10 \%$ of $\bar{\tau} ;$ this yields an uncertainty in $U_{*}$ of $\pm 5 \% \bar{U}_{*}$ The rather high uncertainties assigned to the measurements were determined by an overall system error analysis. The main source of error is due to the large system mass of $4.5 \times 10^{4} \mathrm{~kg}$ being driven by an atmospheric drag force of the order of $0.5 \mathrm{~kg}$, with the resultant system movement, although only a few millimeters, being directly coupled to the flotation fluid motion. A dynamic error analysis was conducted to study this interaction and to find the magnitude of the system errors involved. For this purpose a forcing function generator applied a known amplitude and frequency sinusoidal force to the drag plate. The system response shown in Fig. 8 covers the test range of $0.25-30$ cycles $\mathrm{min}^{-1}$ and shows a natural frequency of about 1 cycle $\mathrm{min}^{-1}$. The relationship between the system response and the forcing frequency indicates an overall system damping constant of about 0.2 of critical (Beckwith and Buck, 1964). The dynamic error expressed as a percent (Fig. 9) has a maximum of $3 \%$ at 4 cycles $\min ^{-1}$ with a decrease thereafter. The dynamic error test results presented in Figs. 8 and 9 were smoothed by hand fitting the curves to area averages shown in Fig. 9 as squares.

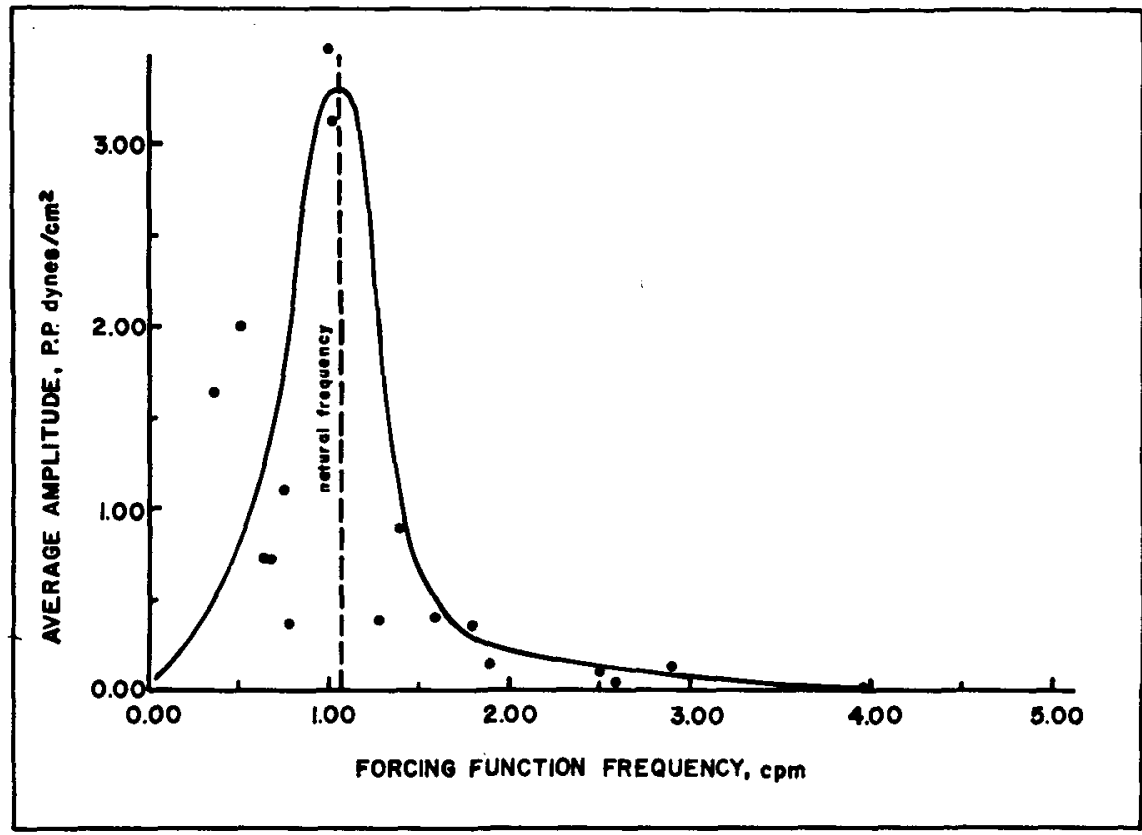

FIG. 8. Drag-plate system response. 


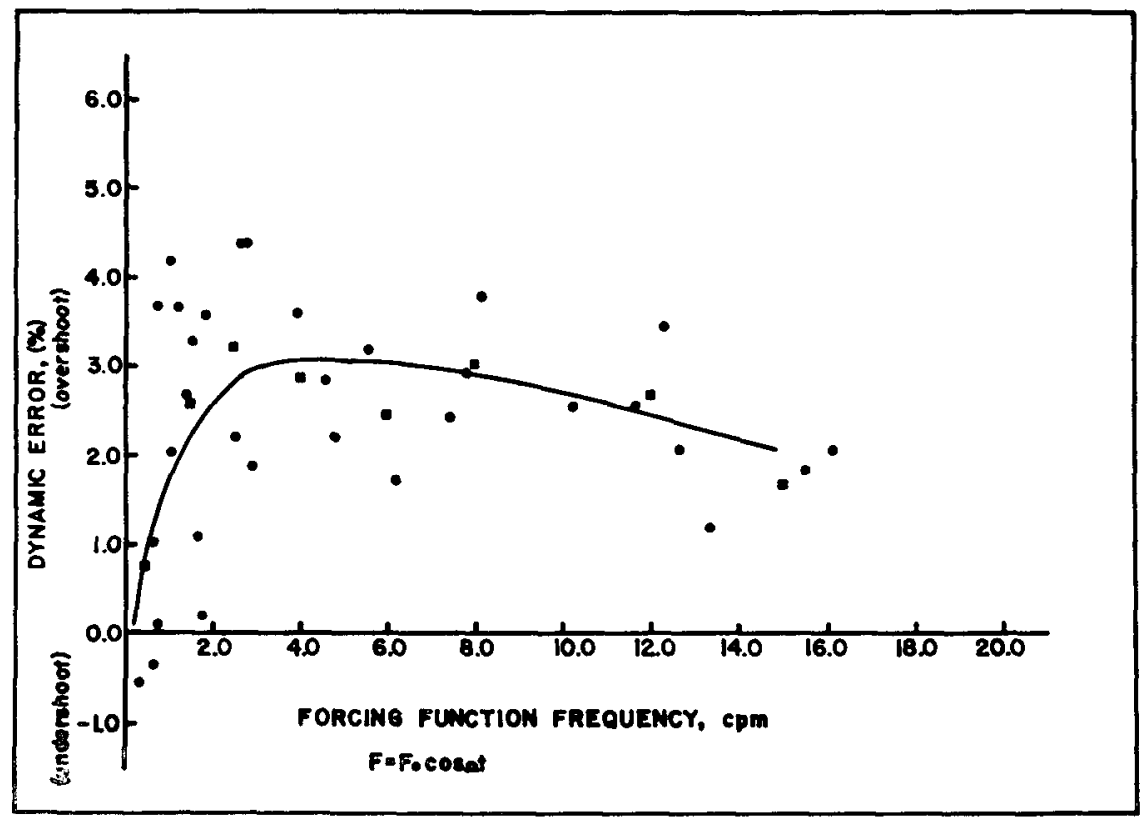

FIG. 9. Drag-plate percent dynamic error.

The drag plate has been used since 1962 in investigations of heat, mass and momentum transfer over a grass turf (Brooks, Pruitt et al., 1962, 1963, 1965; Brooks et al., 1968; Pruitt et al., 1968). The relationship between the horizontal wind velocity profile and friction velocity $U_{*}$ measured by the drag plate has been reported by Goddard (1968). The results have shown that the von Kármán constant is 0.41 and that the log plus linear curvature term alpha has a value near 1.6. The analysis follows the universal function approach used by Monin and Obukhov (1954), and clearly indicates the atmospheric stability limits under which the log plus linear wind velocity equation is valid. The results of this work will be submitted for publication in the near future.

A comparison between shear stress measured by the drag plate, a pressure-sphere anemometer using the Reynolds technique, and the wind profile method is given by Tanner and Thurtell (1969). The results show good agreement between the drag plate and the pressure sphere but show the profile method to yield somewhat higher values of shear stress.

Acknowledgments. I would like to express my thanks to my thesis committee, Profs. C. Lorenzen, L. O. Myrup and W. E. Yates, of the Department of Agricultural Engineering, for their guidance and assistance. Special thanks are expressed to the memory of the late Dr. F. A. Brooks, whose help and encouragement made progress possible. Thanks are also extended to W. O. Pruitt, D. L. Morgan, F. J. Lourence and Ruth C. Laidlaw.

Acknowledgment is also extended to the Atmospheric Sciences Laboratory, U. S. Army Electronics Command, Fort Huachuca, Ariz., whose financial support made the research possible.

\section{REFERENCES}

Beckwith, T. G., and N. L. Buck 1964: Mechanical Measurements. Reading, Mass., Addison-Wesley Publ. Co., 445 pp.

Bradley, E. F., 1968a: A shearing stress meter for micrometeorological studies. Quart. J. Roy. Meteor. Soc., 94, 380-387.

- 1968b: A micrometeorological study of velocity profiles and surface drag in the region modified by a change in surface roughness. Quari. J. Roy. Meteor. Soc., 94, 361-378.

Brooks, F. A., W. B. Goddard and A. T. McDonald, 1968: Analysis in transfer of energy, momentum and moisture near the ground. Rept. under Grant DA-AMC-28-043-66-G26, University of California, Davis.

- W. O. Pruitt et al., 1962: Investigation of energy and mass transfer near the ground including the influence of the soilplant-atmosphere system. Rept. under Contract DA-36-039SC-80334, University of California, Davis.

,--- , et al., 1963: Investigation of energy and mass transfer near the ground including the influence of the soil-plantatmosphere system. Rept. under Contract DA-36-039-SC80334, University of California, Davis.

,-- , et al., 1965: Investigation of energy, momentum and mass transfer near the ground. Final Rept., Grant DA-AMC043-65-G12, University of California, Davis.

Goddard, W. B., 1968: Momentum transfer near the ground. MS thesis, College of Engineering, University of California, Davis.

Hinze, J. O., 1959: Turbulence. New York, McGraw-Hill, 293 pp.

Lettau, H. H., and B. Davidson, 1957: Exploring the Atmosphere's First Mile, Vol. 1. New York, Pergamon Press, 99 pp.

Lourence, F. J., and W. B. Goddard, 1967: A stilling well water level measuring system. $J$. Appl. Meteor., 6, 498-492.

Monin, A. S., and A. M. Obukhov, 1954: Basic regularity in turbulent mixing in the surface layer of the atmosphere. Akad. Nauk. SSSR, Ser. Geofis., No. 24(151), 163-187.

Pasquill, F., 1950: The aerodynamic drag of grassland. Proc. Royal Soc. London, A202, 143-153.

Poppendiek, H. F., and J. E. Vehrencamp, 1950: Investigation of atmospheric diffusion processes by means of experimental, analytical, and numerical techniques. Rept. under Contract 
N6-onr-275, Dept. of Engineering, University of California, Los Angeles.

Priestley, C. H. B., 1959: Turbulent Transfer in the Lower Atmosphere. University of Chicago Press, $130 \mathrm{pp}$.

Pruitt, W. O., and D. E. Angus, 1960 : Large weighing lysimeter for measuring evapotranspiration. Trans. ASAE, 3, 13-18.

- - D. L. Morgan and F. J. Lourence, 1968: Energy, momentum and mass transfer above vegetative surfaces. Rept. under Contract DA-01-086-AMC-0447 (E), University of California, Davis.

Rider, N. E., 1954: Eddy diffusion of mementum, water vapor and heat near the ground. Phil. Trans., A246, 481-501.

Schlichting, H., 1960: Boundary Layer Theory. New York, McGraw-Hill, 487 pp.
Sheppard, P. A., 1947 : The aerodynamic drag of the earth's surface and the value of von Kármán's constant in the lower atmosphere. Proc. Royal Soc. London, A188, 208-222.

Sterns, C. R., 1962: Micrometeorological installation of Lake Mendota. University of Wisconsin, Dept. of Meteorology, Final Rept., Contract DA-36-039-SC-80282.

Tanner, C. B., and G. W. Thurtell, 1969: Anemoclinometer measurements of Reynold's stress and heat transport in the atmospheric surface layer. Res. and Develop. Tech. Rept. ECOM 66-G22-F, Grant DA-AMC-28-043-66-G22, University of Wisconsin, Madison.

Vehrencamp, J. E., 1952: Development of a boundary shear-stress meter. Report under Contract N6-onr-275, Dept. of Engineering, University of California, Los Angeles. 